\title{
PEDAGOGICAL WAYS OF MILITARY UNIVERSITY STUDENTS' PROFESSIONAL EXPERIENCE DEVELOPMENT IN CRISIS SITUATIONS
}

(C) 2019

\author{
Malashenko Leonid Ivanovich, senior researcher of Military Research Center \\ National Defense University named after the First President of the Republic of Kazakhstan \\ (Astana, Republic of Kazakhstan)
}

\begin{abstract}
The paper deals with the role of professional experience in training military specialists to work in modern conditions, associated with the emergence and development of crisis situations that permeate virtually all spheres of society. It is obvious that the existence of any state is unthinkable without professionally trained, qualified and experienced defenders. This increases interest in the development of professional experience of officers as an important component of the readiness for effective action of anti-crisis orientation. The paper shows methodological approaches to the study of the process of military university master's experience development. The author proposes a definition of a military specialist professional readiness on the basis of scientific works analysis. The author also considers distinctive features of the officer's professional experience development. The author defines the main ways of professional experience development in crisis situations for military university undergraduates. They combine theory with practice and research activities, the use of international experience and experience of veterans of wars and military conflicts, pedagogical support of students with the value content of education, differentiation of training with a special position of the teaching staff, with special attention to military university students' professional experience development.

Keywords: professional experience; professional activity; professional readiness; professional competence; ethnocultural competence; military-professional education; professional-value orientation; crisis situation; pedagogical way; pedagogical search; research way; international military collective; differentiated approach; position of teaching staff; mission of military specialist; master student of military higher education institution; national university of defense; national security; military security; coalition of states; collective security treaty organization.
\end{abstract}

\section{УДК 37.02}

DOI 10.24411/2309-4370-2019-11311

Статья поступила в редакцию 09.11.2018

\section{ПОНЯТИЕ О РУССКОМ МИРЕ ПРИ ФОРМИРОВАНИИ СОЦИОКУЛЬТУРНОЙ КОМПЕТЕНЦИИ У ИНОСТРАННЫХ СТУДЕНТОВ}

(C) 2019

Марчук Светлана Владимировна, аспирант кафедры общей педагогики, истории педагогики и образования; преподаватель кафедры русского языка Ленинградский государственный университет им. А.С. Пушкина (2. Санкт-Петербург, Российская Федерация); Военно-морская академия им. Адмирала Флота Советского Союза Н.Г. Кузнецова (2. Санкт-Петербург, Российская Федерации)

Аннотация. Автором проводится анализ понятия Русский мир, ставшего устойчивым оборотом не только в России, но и за рубежом. Предлагается обоснование понятия Русский мир в историческом, педагогическом, психологическом и философском аспектах. Автор статьи интерпретирует основной смысл этого понятия для освоения традиций Русского мира иностранными студентами, изучающими русский язык как иностранный. Статья нацелена на формирование социокультурных компетенций иностранных студентов благодаря верному преподнесению понятия Русский мир. Предлагается обоснование концепции понятия Русский мир и возможные приёмы обучения. Автор уверен, что на преподавателя возлагается ответственность верно преподносить информацию обучающимся. Значит, обучение иностранных студентов в общем и частном зависит от подготовленности преподавателя: его идеологии, знаний и методики преподавания. Особенно важно, на взгляд автора, изучение предложенной темы в настоящее время.

Ключевые слова: коммуникативная компетенция; социокультурная компетенция; понятие; понятие Русский мир; русская идея; традиции; русская диаспора; этнос; культура; концепция; лингвострановедение; фонд «Русский мир»; учебный сайт; мультимедийные технологии; информационная культура; интернетресурсы.

Формирование коммуникативных компетенций при обучении русскому языку иностранцев является основополагающим, потому что компетентность характеризует уровень владения языком и включает в себя лингвистическую, речевую и коммуникативную компетенции.

Следует отметить, что коммуникативная компетенция включает в себя социокультурную, которая подразумевает знание изучающими иностранный язык национально-культурных особенностей социального и речевого поведения носителей языка (их обычаев, этических норм, социальных и культурных стереотипов, знаковых моментов истории и культуры), а также умение пользоваться этими знаниями в процессе общения [1].

В социокультурную компетенцию входят прежде всего знания, связанные со сведениями о стране изучаемого языка, духовных ценностях и культурных 
традициях, особенностях национального менталиmета. Социокульурный подход к обучению должен быть ориентирован на усиление культуроведческого аспекта в содержании обучения [2].

Следовательно, коммуникативная компетентность преподавателя позволит заполнить лакуны культурного фона, то есть раскрыть смысл понятий, принадлежащих чужой культуре. Являясь главным модератором при формировании знаний, преподаватель-наставник должен скрупулёзно подбирать и излагать материал для изучения, иметь чёткую убеждённость в предлагаемой информации.

В основе особенностей национально-культурного этноса России заложена русская идея, или Русский мир, понятие которого важно транслировать верно и в полной мере.

Обращение к определению понятия Русского мира является актуальным в свете неустойчивых идеологических взглядов и фальсификации исторических фактов.

На начальном этапе исследования нас интересовало, для чего нужно осваивать традиции Русского мира иностранным студентам и как знание этих традиций может повлиять на пребывание и обучение иностранцев в России. Привлекает внимание в аспекте проблематики нашего исследования верное оформление выражения Русский мир - в частности, необходимость применения кавычек.

В качестве изначального пункта в научной характеристике обучения приемлемо обоснование К.Д. Ушинского, который в дидактике делал упор на психологию. С когнитивной позиции - это чувственное восприятие. «...Способность чувствовать и сравнивать и различать предметы своих ощущений есть сознание; способность обращать мысль на саму себя, наблюдать не предметы чувства, а само чувство; не только желать, но и думать о собственном желании, - это и есть самосознание, корень свободы выбора, языка, психологии, философии, логики, грамматики, эстетики...», - пишет выдающийся педагог, психолог, учёный К.Д. Ушинский [3, с. 61].

То же о чувственном восприятии трактует и философ К.А. Гельвеций: «Физическая чувствительность - это сам человек и источник всего того, чем он является. Поэтому знания человека никогда не достигают большего, чем дают его чувства. Все, что недоступно чувствам, недостижимо и для ума» [4].

Следует отметить, что знакомство с традициями Русского мира иностранцев - это и есть первая ступень, то есть их чувственное восприятие увиденного, услышанного о стране, учиться в которой им предстоит.

Формировать убеждения иностранным студентам важно во время прохождения адаптационного периода, который является основополагающим в познавательном процессе целостного отражения предметов и явлений объективного мира.

Для того чтобы освоение традиций Русского мира иностранными студентами было в правильном изложении, необходимо разобраться в самом понятии Русский мир, или «русская идея».

Историками, страноведами доказано, что понятие Русский мир имеет долгую историю и уходит корнями в прошлое. В последние годы это словосочетание встречается довольно часто, но употребляется и в кавычках, и без них. В связи с этим необходимо внести ясность: нужны ли кавычки в устойчивом выражении Русский мир и что включает в себя это понятие.

Приступая к исследовательскому анализу понятия Русский мир, важно знать, что понятие - это продукт, мысль, множество, совокупность представлений, общее имя. Предметы, явления и связи между ними должны быть отражены в обобщённой форме. Понятие не статично, но определения, мысли, пространственно-временные отношения взаимосвязаны. Одна из логических форм мылления, высший уровень обобщения [4, с. 204].

«Панта рей», то есть «всё течёт, всё меняется, но и пребывает одновременно», - так мыслил древнегреческий философ Гераклит. В самом деле, чтобы остаться самой собой, река должна всё время течь [5, c. 15]. Так, русский народ, спустя сотни лет, несмотря ни на что, сохраняет свою идеологию.

Глубокое и всестороннее рассмотрение аспектов, связанных с идеей Русского мира, можно найти у профессора В.И. Фатющенко. Исследуя эту тему, учёный-историк писал: «Трудно дать чёткое определение Русской идее, и чтобы понять, нужно вживаться в сам процесс формирования этой идеи. В области культуры она выражена в философии и публицистике, в живописи и в музыке, в художественной литературе и религиозных представлениях, в градостроительстве и архитектуре. Понятия «национальная идея» и «Русский мир» связаны как с русским, так и с другими народами и имеет своё предназначение в истории человечества» $[6$, с. 156,158$]$. Определённо, учёный верно трактует предназначение всего «русского».

Также необходимо заметить, что цивилизация Русь - Россия состоит из нескольких слоёв: христианского с византийским влиянием, азиатского и западного, но основной цивилизацией является всётаки народ, население. И это необходимо учитывать при определении понятия Русский мир.

По-философски выразился Максим Горький о русском этническом качестве через убеждения Л.Н. Толстого, который «...воплотил в огромной душе своей недостатки нации, все увечья, нанесённые пытками истории страны нашей; «анархизм Толстого» в корне и по существу выражает антигосударственность, черту истинно национальную» [7, с. 313].

В поэме Н.А. Некрасова «Кому на Руси жить хорошо» глава «Пир на весь мир» начинается словами:
«Ты и убогая,
Ты и обильная,
Ты и могучая,
Ты и бессильная,
Матушка Русь!» [8, с. 410]

Мысль поэта ещё раз показывает, что русская идея сформировывалась не целенаправленно, не по заданию, а естественно. В поисках и муках ищет Россия свой путь, переосмысливая, переоценивая, совершая порой непоправимые ошибки, но сохраняя предписанный свыше замысел. В связи с этим выстроить чёткий список идейного содержания понятия Русский Мир очень сложно. 
Уместно обратить внимание на высказывания представителей социально-философской мысли (Н.Я. Данилевский, Л.Н. Гумилёв, Н.С. Трубецкой), которые отмечают, что национальная специфика России создаётся по цивилизационному принципу, т.е. разнообразные нации со своими религиозными представлениями и специфической культурой объединяются единым цивилизационным типом» [9, с. 129]. Это ещё одна особенность, вложенная в русскую идею.

Значит, государство русское формировалось из племён путём объединения разных народностей, поэтому характерной чертой Русского мира является его многообразие, которое проявляется в многонациональности, геополитической разбросанности, но имеет общую культуру, а главное - язык.

Так, исследования в области русской идеи выражаются в разных концепциях.

Политолог О.Н. Батанова в своей работе «Русский мир и проблемы его формирования» характеризует Русский мир как «глобальный культурно-цивилизационный феномен, состоящий из России как материнского государства и русского зарубежья, объединяющий людей, которые независимо от национальности ощущают себя русскими, являются носителями русской культуры и русского языка, духовно внутренне связаны с Россией и неравнодушны к её делам и судьбе» [10]. Согласиться с мнением учёного - значит признать всех эмигрировавших из страны приверженцами Русского мира, русского народа. Это невозможно, потому что одним из критериев русской идеи является патриотизм.

Также необходимо упомянуть о Фонде «Русский мир», созданном в 2007 году при поддержке президента страны, возглавляемом В. Никоновым. Целью этого Фонда является объединение многочисленной русской диаспоры за рубежом. В рамках этого проекта Россия должна «обрести новую идентичность, новую возможность эффективного сотрудничества с остальным миром и дополнительные импульсы собственного развития», - так объясняет суть проекта председатель правления Фонда «Русский мир» [11, c. 12].

Но правомерно ли будет считать идею Фонда «Русский мир» тождественной русской идее с её историческими корнями и традициями?

На мой взгляд, искусственно созданный Фонд с очень серьёзным названием «Русский мир», в состав которого входит эмигрантское предпринимательство, расселившееся за пределами своей исторической родины, фальсифицирует понятие Русского мира как парадигму идеологии Государства российского.

Относительно вышеизложенного важно заметить, что иностранные студенты, прибывшие в Россию получить образование, должны осваивать традиции Русского мира в исторической концепции этого сложного и многозначного понятия. Исследования показывают, что Русская идея формировалась в гуще событий всех сословий этноса на протяжении многих веков.

Таким образом, для иностранных студентов понятие Русский мир при освоении традиций должно преподноситься без кавычек и упоминания о Фонде
«Русский мир». Но знакомство с литературой, живописью, музыкой, авторами которых являлись представители русского зарубежья, необходимо в рамках освоения русских традиций.

Выясняется, что широкий диапазон культуры, создававшийся не менее 1000 лет, производит неизгладимое впечатление на иностранных студентов, приехавших в нашу страну целенаправленно.

Надо отметить, что очень важным будет знакомство с летописями, мемуарами, где подробно описывается прошлое России. Например, сборник «Московская старина: воспоминания москвичей прошлого столетия» представляет мемуары московских бытописателей Н.В. Давыдова, П.И. Богатырёва, Д.А. Покровского, Н.Д. Телешова и др. мемуаристов, принадлежавших к различным классам, сословиям, культурным слоям и профессиональным кругам общества, проживавшим в Москве в период XVIII-XIX веков. Ценностью является жизнеописание жителей столицы: их быта, традиций, торговой сферы, обрядов, устоев и т.д. Благодаря мемуарам современному поколению в детальном изложении возможно представить жизнь «из первых уст» [12].

С нравами, традициями, имеющими нравственное значение для народности, полезно знакомить студентов посредством изучения лингвострановедения, которое «первоначально трактовалось как область методики, связанная с исследованием путей и способов ознакомления иностранных учащихся с действительностью страны изучаемого языка в процессе овладения иностранным языком и через посредство этого языка. В дальнейшем этот термин стал трактоваться как методическая дисциплина. Проблематику лингвострановедения составляют два круга вопросов: лингвистические и методические» [4, с. 128].

Например, пословищы, поговорки и фразеологизмbl являются ярким примером и средством для познания культуры русского народа.

Также традиции русского гостеприимства, которые формировались веками и приобрели свой особый статус. К примеру, «традиции питания, которые играют огромную роль, даже жизненно важную в истории народов. "Человек есть то, что он ест"», - гласит народная мудрость» [13, с. 357].

«Тема дороги важна для любой культуры. Дорога в России - это не просто путь, проложенный между населёнными пунктами, это её судьба». Не узнаешь дорог в России, не сможешь понять что-то очень важное, достижимое только русской душе [13, c. 312].

Семейная жизнь, положение женщины в России тема важная, актуальная и в настоящее время. «Семья в любом этносе первостепенна. В России она также составляла хозяйственную и нравственную основу жизни людей» [14, с. 306].

Православие особенно повлияло на русский характер. Русский философ В. Соловьёв в центр понятия Русский мир ставит принадлежность к религии, которая оказала влияние на уклад русской жизни, мировосприятие. Например, «...такое чисто русское понятие, как смирение. Все попытки перевести его на иностранный язык терпят неудачу, при переводе смысл теряется» $[14$, с. 499$]$. 
Необъятная территория - это отдельный пласт культуры. Диалекты, внутренние традиции и устои, различие климатических условий, многообразие полезных ископаемых, лесостепи и степи, реки и т.д.

Сказочные герои Баба Яга, Иван Царевич, Ивандурак - неотъемлемая часть русских традиций, сопровождающих с раннего детства всякого, кто связан с Россией.

Особенную значимость имели победоносные военные битвы и сражения, в результате которых смерть и разрушения лишь закаляли русский характер ещё сильнее. Более семидесяти лет прошло по окончании Великой Отечественной войны 19411945 гг. - самой кровопролитной войны в истории мира, и победителем в этой битве, бесспорно, можно считать русскую загадочную душу.

Нельзя не отметить, что Русский мир в недалёком прошлом был сообразен советскому. В советский период русский человек воспринимался как представитель советского строя, поддерживающий исконнорусские традиции.

Наконец, в традициях Русского мира важнейшим фактором является русский язык, как создание народное, развивающееся из поколения в поколение. К.Д. Ушинский писал: «Язык народа - лучший, никогда не увядающий и вечно вновь распускающийся цвет всей его духовной жизни, начинающийся далеко за границами истории. В языке одухотворяется весь народ и вся его родина» [15, с. 367].

Таким образом, отечественный язык, русские традиции имеют глубокие корни и богатое историческое прошлое, и в связи с этим понятие Русский мир необходимо употреблять без кавычек и с заглавной буквы.

Опираясь на труды психологов, дидактиков, методистов и историков, в той или иной мере исследовавших проблему Русского мира, русской идеи, а также на собственные теоретические поиски, мы считаем многовековое историческое наследие Русского мира концепцией исследуемого понятия при обучении иностранных студентов русскому языку как иностранному.

Для иностранных студентов важно создавать специальные программы и условия для освоения традиций Русского мира в глубоком смысле этого понятия. А формировать представления о России с верной позицией возможно через планомерное изучение русского этноса, которое должно стать мотивацией для изучения русского языка.

Но надо отметить, что иностранные студенты по прибытии в Россию сталкиваются с различного рода трудностями. В настоящее время для упрочения отношений в международной образовательной среде проводится много социологических исследований для улучшения адаптационного периода. Создаются группы для проведения межкультурных праздников, фестивалей. Иностранных студентов поселяют совместно с русскими студентами в общежитии. Как выясняется, необходимо усилить работу по адаптации в стране временного, но длительного проживания. Как считает профессор Флоридского университета Мирка Коро-Льюнберг, иностранные студенты, которые активно включены в жизнь общества страны пребывания, получают больше удовлетворения от учёбы и более охотно принимают участие в общественной и научной жизни [16].

Необходимо учитывать, что прибывающие иностранные студенты зачастую обладают недостоверной, искажённой, а порой негативной информацией о культуре нашей страны. Стереотипы и предубеждения осложняют и так довольно непростой этап адаптации в неродной стране.

Важно учесть, что $91 \%$ опрошенных иностранных студентов указали на интерес к изучению русских традиций и культуре других народов, с представителями которых они общаются [17].

Таким образом, ретроспективный анализ исследований, посвящённых проблеме верного обоснования понятия Русский мир, позволяет сделать следующие выводы: социокультурная компетенция изучающих русский язык как иностранный возможна в случае правильного толкования и грамотного преподнесения информации.

Отсутствие информационной культуры - проблема мирового уровня, поэтому задача педагога задать правильный вектор и контролировать выбор информации.

Современные мультимедийные технологии большая помощь в формировании коммуникативной компетенции. Преподаватель имеет возможность использовать презентации, показывать и снимать фильмы, использовать учебные сайты.

Так, автор статьи использует сайт www.info. lanaimage.com уже на протяжении четырёх лет и имеет только положительные результаты. Обратная связь через сайт позволяет давать непосредственные задания, консультировать, делать ссылки на нужные учебно-познавательные материалы.

Опыт с учебным сайтом как средством персонального взаимодействия для формирования коммуникативной компетенции иностранцев показывает, что знакомить с национальными традициями, обучать способности извлекать из языка страноведческую информацию и пользоваться ею является важным, интересным и удобным способом и для студентов, и для преподавателей. Этот способ обучения можно использовать как для подготовки к мероприятию или новой теме, так и для анализа проведённого.

Например, посещение виртуальных экскурсий, связанных с местами боевой славы не только Великой Отечественной войны 1941-1945 гг., но и других важных исторических сражений возможно при наличии интернет-ресурса, в частности учебного персонального сайта.

Прослушивание памятников древнерусской литературы с комментариями и переводом на современный язык.

Документальные фильмы о почётных гражданах России, ветеранах, писателях.

Исторический анализ дружбы России с другими странами.

Изучение пословии и поговорок, в которых «заложена национально-культурная семантика языка, т.е. языковые значения, которые отражают, фиксируют и передают от поколения к поколению особенности русской природы, экономики России, общественного устройства, фольклора, художественной литературы, 
искусства, науки, подробности быта, и обычаев народа» $[18$, с. 4$]$.

Подготовка к проведению праздников с соблюдением сохранившихся традиций, изучение песенного фольклора.

Изучающим русский язык как иностранный важно дать понять, что Русский мир по-прежнему является квинтэссенцией идеологии государства.

Таким образом, преподавателю необходимо верно обосновывать понятие Русского мира при обучении иностранных студентов. На преподавателя возлагается ответственность верно преподносить информацию.

Значит, обучение иностранных студентов в общем и частном зависит от подготовленности преподавателя: его идеологии, знаний и методики преподавания. Неверное толкование понятия Русский мир, базовом в формировании социокультурной компетенции, приводит к непониманию между участниками коммуникации, что недопустимо для позитивного отношения к русскому языку и к России.

\section{Список литературы:}

1. Габдрахманова П.Л., Богатова Е.Н., Мустафина Л.Р. Развитие коммуникативной компетенции в онлайн среде обучения РКИ: возможности и перспективы // Образовательные технологии и общество. 2017. Т. 20, № 2. С. 329-345.

2. Азимов Э.Г., Щукин А.Н. Новый словарь методических терминов и понятий (теория и практика обучения языкам). М.: Издательство ИКАР, 2009. $448 \mathrm{c}$.

3. Ушинский К.Д. Собрание сочинений: в 11 т. Т. 10: материалы к третьему тому «Педагогической антропологии» / редкол.: А.М. Еголин (гл. ред.), Е.Н. Медынский и В.Я. Струминский. М.; Л.: Акад. пед. наук РСФСР, 1950. 665 с.

4. Гельвеций К.А. О человеке // Соч. в 2 т. Т. 2. М., 1974. С. 555.

5. Философия для студентов вузов / С.И. Самыгин [и др.]. Изд. 9-е, стер. Ростов-на-Дону: Феникс, $2011.154 \mathrm{c}$.

\section{«RUSSIAN WORLD» CONCEPT IN THE COURSE OF FOREIGN STUDENTS' SOCIOCULTURAL COMPETENCE DEVELOPMENT}

(C) 2019

Marchuk Svetlana Vladimirovna, postgraduate student of General Pedagogy,

History of Pedagogy and Education Department; lecturer of Russian Language Department Pushkin Leningrad State University (Saint Petersburg, Russian Federation); The Naval Academy named after Admiral of the Fleet of the Soviet Union N.G. Kuznetsov (Saint Petersburg, Russian Federation)

Abstract. In this paper the author analyzes the «Russian world» concept which has become a stable term in Russia as well as around the world; the analysis of the concept is accompanied by teaching the Russian language to foreign students. The author describes how foreign students can use knowledge of the Russian world traditions during their stay in Russia while learning the Russian language. The author also explains why the concept of the Russian world should be written without quotation marks. Ideological postulates are being assessed critically. A new approach to the Russian world concept is offered taking into account historical and philosophical consequences. The author of the paper interprets the main sense of the concept for studying the Russian world traditions by foreign students who learn the Russian language. The aim of the paper is to develop sociocultural competence with the help of an adequate interpretation of the Russian world concept to foreign students who learn the Russian language. The author considers that a teacher (an instructor) is responsible for correctness and completeness of the information given to students. Hence teaching foreign students depends on teachers' (instructors') ideology, knowledge and methods of teaching. According to the author it is especially important to study the offered subject at present.

Keywords: concept (conception) or terms; Russian world; Russian idea; traditions; Russian diaspora; ethnos; culture; concept; country studies; Russian World fund; educational website; multimedia technologies; information culture; Internet resources. 